
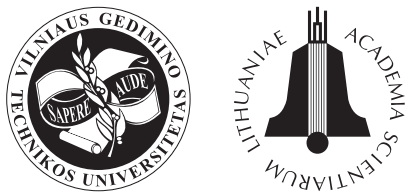

TRANSPORT

2010

25(2): 155-162

\title{
TRAFFIC AND ENVIRONMENTAL STREET NETWORK MODELLING: BELGRADE CASE STUDY
}

\author{
Jadranka Jović ${ }^{1}$, Vladimir Đorić ${ }^{2}$ \\ Transport and Traffic Engineering Faculty, University of Belgrade, \\ Vojvode Stepe 305, Belgrade, Serbia \\ E-mails: ${ }^{1}$ j.jovic@sf.bg.ac.rs; ${ }^{2}$ v.djoric@sf.bg.ac.rs
}

Received 20 April 2009; accepted 20 May 2010

\begin{abstract}
The paper presents a procedure for modelling transport demand and analyses effects caused by changes in the characteristics of street network exploitation. Based on the effects of the measures predominantly connected with speed restrictions on characteristic sections, the Scenarios resulting in reduced congestion during peak hour and a decrease in harmful effects of traffic were selected. A rough effectivity analysis of transport vehicle kilometres travelled and travel time on the network was carried out. Transportation modeling is the most efficient way to analyze the effects of traffic solutions. Once established, transport model brings only benefits in future projects. Speed reduction strategy was easily simulated using the transportation modeling procedure. Other sustainable transport and mobility management strategies considering sustainable transportation could also be simulated.
\end{abstract}

Keywords: transportation planning, transport demand modeling, environmental calculation, speed scenarios, road transport emissions.

\section{Introduction}

The first step in solving the problems encountered in the transport system is to establish a unique database with the aim to give the planners a good initial basis (a model of the existing state) for the quantification of data relevant to the procedures of modelling, predicting and testing variants for the future development of the transport system.

In addition to traffic criteria, modelling may be performed on the basis of environmental criteria related to the emission of noise and hazardous gases into the atmosphere.

According to methodology deffined in Transportation Planning Laboratory (PLASA) on Traffic and Transport Engineering Faculty in Belgrade, a large scale research was conducted during the period 2004-2007. Transport Model of Belgrade was formed as a part of previous scientific and research efforts.

This idea was carried out through the process of creating Belgrade Transport Model applying it in the analysis of transport demand on Belgrade traffic network. The conducted analysis was made as a part of planning documentation (Jovic et al. 2007, 2008).

The transport model of Belgrade implies a set of relevant data (numeric, graphic etc.), indicators, parameters and simulation models expressed in space and time. The general application purpose of the Transport Model is to serve as an official basis for calculations to authorities or organizations the activities of which are directly linked to planning, programming, managing and building the transport system and as a basis for various research and scientific projects, appraisal processes, analysis of traffic regime optimal solutions, intelligent transport systems in the portion of dynamic traffic control etc. (Jovic 2003; Jovic et al. 2007, 2008).

A lot of scientific and research projects resulted from Transport Model of Belgrade. Project results and collected experience denote the importance of traffic modeling and environmental calculation in procedures of traffic solutions evaluation. Tested solutions are consistent with the concept of sustainable transport. Case Study presented in this paper came as a result of hypotheses and solution scenarios generation according to infrastructure capabilities and expert experience.

Sustainability is not about threat analysis; sustainability is about systems analysis. Specifically, it is about how environmental, economic, and social systems interact to their mutual advantage or disadvantage at various space-based scales of operation (Toward a Sustainable Future 1997; Urban Environmental Management ... 2009).

Sustainability and sustainable transportation are difficult to measure directly, so various performance in- 
dicators are used to evaluate them. The focus can be on a single impact, such as air pollution emissions, or a wider range of effects (Litman 2010a, 2010b; Online TDM Encyclopedia 2009).

As road transport is a major source of air pollutant emissions in European cities an efficiency assessment of possible future measures to reduce air pollution is required for future traffic planning, regulatory and fiscal initiatives (Lumbreras et al. 2008).

Traffic speed reductions have mixed air emission impacts, depending on traffic conditions, driving conditions, vehicle type and which emissions are considered. The speed dependency of the pollutant emissions using available emissions data and functions are known in the literature (André and Hammarström 2000; New Directions ... 2009; Török 2009; Kuprys and Kugelevičius 2009; Kovács and Török 2010).

Transportation modeling is the only way to forecast the need for transport in future and the behavior of the system participants, as well as to plan actions for the implementation of the future scenarios. Also, modeling is the only economical and sufficiently reliable way to carry out a forward assessment of the impact of the innovations to be applied on the overall system (UšpalytėVitkūnienè et al. 2006; Tanczos and Torok 2008; Daunoras et al. 2008; Kinderytė-Poškienè and Sokolovskij 2008; Bazaras et al. 2008; Burinskienè and Rudzkienè 2009; Burinskienè 2009; Mačiulis et al. 2009; Szűcs 2009; Filipović et al. 2009; Paslawski 2009).

This paper presents the procedure of transport demand modeling and environmental analysis of the effects caused by changes in the street network exploitation characteristics applied to a Case study.

The aim of the paper was to present a transportation modeling procedure with environmental impact calculation in order to quantify the effects of traffic solutions according to principles of sustainability and mobility management strategies. This procedure would enable estimation of traffic pollution in the future in different time periods (hour, day, year).

The procedure like this, that combines traffic modeling and environmental calculation, was not applied in countries of South-East Europe.

\section{Case Study}

Belgrade, the biggest city on Balkan Peninsula, is the capital of Serbia with approximately 1.5 million inhabitants. It is located on Corridor $\mathrm{X}$ and represents a significant traffic node in the region (Smartplan Beograda 2001).

The total length of the street network in the existing state is $1686 \mathrm{~km}$. About $67 \%$ of the primary urban street network is with a single lane per direction. The network consists of 5900 links and 2398 nodes. The elements required to generate the state in the future time horizons are added through the future urban street network (street network of the year 2021).

Transport demands are defined through a number of spatial distribution matrices determined on different time periods, purposes and modes of movement.
The matrices used in this paper relate to passenger car trips during the morning peak period. In the existing state, the specific matrix has 60000 vehicles, whereas the number of passenger cars in the forecasted year amounts to 79530 passenger cars during a peak hour.

The most important projects in Belgrade include the completion of Belgrade Bypass and construction of one bridge over the Sava River (Fig. 1). The mutual goal of these two projects is to provide significant unloading of Belgrade street network, particularly the urban highway relocating transit flows of heavy freight vehicles to the Bypass first and providing an alternative with one more bridge over the Sava River within the Inner SemiRing Road second. The urban highway in the territory of Belgrade is a part of Corridor X (Fig. 1) (Jovic et al. 2006; Vuchic 1999).

Due to such development of Belgrade infrastructure, the need to model and analyse traffic load in the zone of alternative crossings (the Old Gazela bridge and the New bridge over the Sava River) with several solutions and to perform basic environmental analysis have arisen which would help in envisaging and quantifying the impact these traffic infrastructure facilities would have on their surrounding from the environmental point of view. The basis for this modelling is the Transport Model of Belgrade 2021 with the road network (with the values of section characteristics - capacity, free flow speed, rank, road profile - for the year 2021).

The subject of this analysis was a portion of 2021 network comprising the following traffic routes:

- a part of the urban highway passing through Belgrade with the Old Gazela bridge;

- a planned urban highway alternative, the New bridge over the Sava River and the tunnel under the Topčider Hill;

- transverse connections between specified directions at the beginning and end of the observed area and central transverse connection across Belgrade Fair.

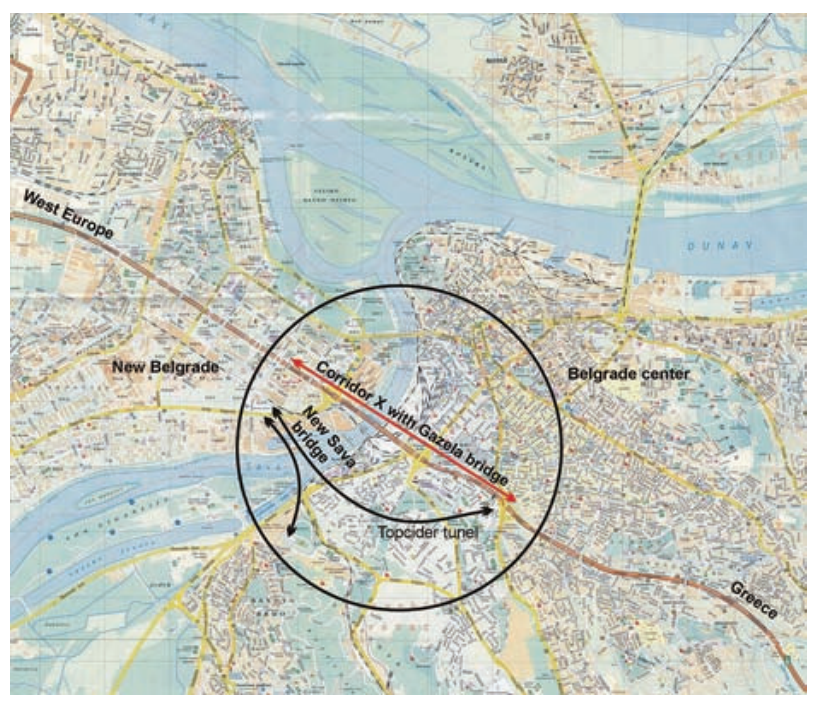

Fig. 1. Greater area of interest 
By changing the values of free flow speeds in the tunnel and on the urban highway, 5 network Scenarios were created and then tested in the Model.

Speeds in different Scenarios (Table) are estimated according to a survey on the present street network and measures to be applied in the future traffic management system.

An overview of solution Scenarios

\begin{tabular}{ccc}
\hline Scenarios & $\begin{array}{c}\text { Free flow speed in } \\
\text { tunnel } V_{0 t}\end{array}$ & $\begin{array}{c}\text { Free flow speed on } \\
\text { urban highway } V_{\text {Ohw }}\end{array}$ \\
\hline Scenario 1 & $V_{0 t}=80 \mathrm{~km} / \mathrm{h}$ & $V_{\text {Ohw }}=80 \mathrm{~km} / \mathrm{h}$ \\
\hline Scenario 2 & $V_{0 t}=60 \mathrm{~km} / \mathrm{h}$ & $V_{0 h w}=80 \mathrm{~km} / \mathrm{h}$ \\
\hline Scenario 3 & $V_{0 t}=60 \mathrm{~km} / \mathrm{h}$ & $V_{\text {Ohw }}=60 \mathrm{~km} / \mathrm{h}$ \\
\hline Scenario 4 & $V_{0 t}=50 \mathrm{~km} / \mathrm{h}$ & $V_{0 h w}=80 \mathrm{~km} / \mathrm{h}$ \\
\hline Scenario 5 & $V_{0 t}=80 \mathrm{~km} / \mathrm{h}$ & $V_{0 h w}=60 \mathrm{~km} / \mathrm{h}$ \\
\hline
\end{tabular}

These Scenarios were created on the basis of a system modification Scenario and the real possibility of applying management measures in order to obtain the desired effects (speeds).

\section{Modelling Procedure}

Modelling transport demands and environmental indicators was conducted in several steps:

Step I. Coding Belgrade traffic network primarily refers to entering new sections planned on Belgrade traffic network for the target year 2021. This specific area of particular significance covers the New Bridge over the Sava River and the tunnel under the Topčider Hill. It was essential to define capacities, free flow speeds, the number of lanes and the way of intersecting the existing road network. As regards the networks reserved for the movement of freight vehicles, it was necessary to prohibit the movement of freight vehicles on the portions of a lower-rank network.

Step II. The definition of VD function includes the legality of speed variation (from free flow speed to operating speed) related to the traffic flow that is the same for all Scenarios and is provided in the form of VD function (volume delay function). BPR function (U.S. Bureau of Public Roads) was used as a basis for defining VD function that can be expressed in the following form:

$$
t_{c u r}=t_{0}\left(1+a\left(\frac{q}{q_{\max } \cdot c}\right)^{b}\right) .
$$

With reference to data about travel times on Belgrade network and exit routes, 9 variants of BPR function (including various parameters $a, b$ and $c$ ) corresponding to road/street categories defined for Belgrade traffic network were formed (Vukanovic et al. 2006; Vukanovic 1997).

Step III. Network loading is loaded with travel matrices during the morning peak hour (from 07:00 to 08:00 hour) for passenger cars and freight vehicles in the forecasted state (year 2021). During a peak hour in 2021, the passenger car movement matrix has $79528 \mathrm{PA} / \mathrm{h}$. It was obtained on the basis of the existing matrix (year 2005) and the predicted change in socio-economic indicators (primarily number of inhabitants). The existing matrix was obtained on the basis of traffic surveys (household interviews) conducted in Belgrade during 2005 and made $57444 \mathrm{PC} / \mathrm{h}$. Socio-economic indicators were obtained on the basis of 2002 census. The factors by which the matrix was calibrated to the target year were obtained on the basis of population growth forecast and the predicted change in the level of motorization. In this process, different factors were defined for central and peripheral zones in Belgrade.

The freight vehicle trip matrix was produced calibrating the matrix of the existing state obtained by counting vehicles on the outer cordon and an interview conducted at freight terminals. The matrix containing 2589 $\mathrm{FV} / \mathrm{h}$ was processed, whereas it was taken into account that Belgrade Bypass should be completed, which will considerably impact the structure of traffic flow on the urban highway and trunk roads.

Step IV. Selecting indicators of traffic network volume. Traffic flows on a specific traffic network were analysed and then compared with the defined capacities to obtain capacity utilizations per sections. In addition, a drop in speed due to congestion was indicated through the values of free flow speeds and operating speeds on the network.

Step $V$. Selecting environmental parameters (Fig. 2). The same parameters related to noise and pollution transformation were used for all Scenarios in the analysis.

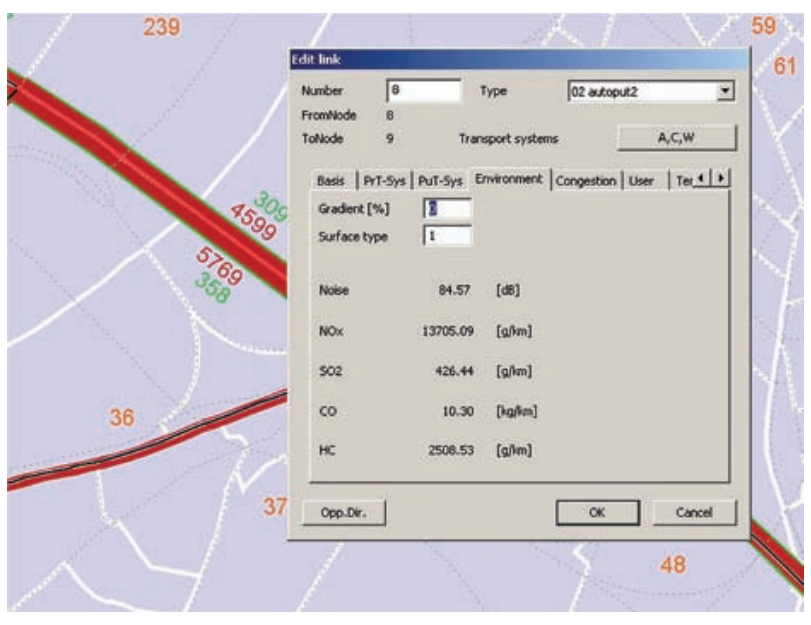

Fig. 2. Environmental indicators ered as:

All parameters offered by software were consid-

- noise $(\mathrm{dB})$ - level of noise generated by vehicles in traffic flow;

- $\mathrm{NO}_{\mathrm{x}}(\mathrm{g} / \mathrm{km})$ - level of nitrogen oxide;

- $\mathrm{SO}_{2}(\mathrm{~g} / \mathrm{km})$ - level of sulphur-dioxide;

- CO $(\mathrm{kg} / \mathrm{km})$ - level of carbon-monoxide;

- HC (g/km) - level of hydrocarbon. 
Noise determination procedure based on RLS 90 (VISUM 10.0 User Manual 2007) was given preference over the Nordic procedure because it was regarded to be more suitable for the data obtained measuring noise on the urban network.

The procedure for calculating the level of the exhaust gasses of various pollutants is complied with the emission factors of the Swiss Federal Office for the Environment. The values depend on traffic flow in both directions, the percentage of freight vehicles in the flow and user defined parameters (VISUM 10.0 User Manual 2007).

\section{Modelling Results}

The most loaded sections in all Scenarios are the sections on Corridor X, to be more specific, the sections on the Old Gazela Bridge over the Sava River. Numbers 1 and 3 in Fig. 3 denote interchanges at which maximum load occurs. These sections, normally, sustain the greatest load because they are the points where the urban highway intersects intensive urban trunk routes. Marks C1 to $\mathrm{C} 3$ denote transversal connections. Interchanges and transversal connections are numbered according to their significance. In the following text above, the presented marks will be used for the convenience of reference.

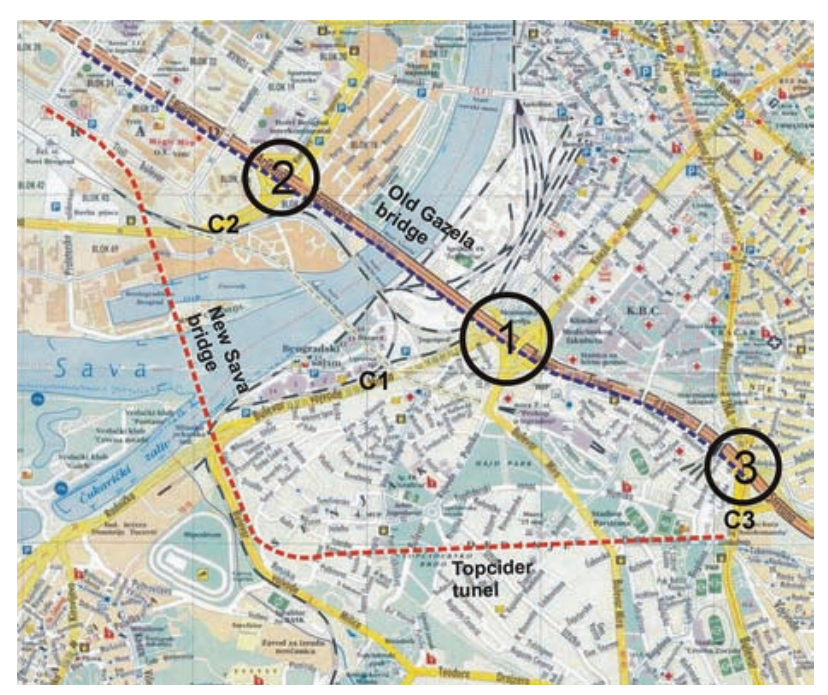

Fig. 3. Scope of analysis

Traffic planning methodology presumes that intersections are treated as points. Therefore, for traffic planning needs, when coding the network, it is necessary to simplify grade-separated interchanges which is the main reason for such high capacity utilisation values on interchange sections and that is why the values on the sections with the real traffic flow values are given the central position.

\section{Scenario 1:}

The most loaded section on the network in Scenario $\mathrm{S} 1$ is the Old Gazela bridge section $\left(Q_{c}=5.769 \mathrm{PA}\right)$ in the direction towards the city centre the flow of which exceeds the capacity $(q / C=111 \%)$ and the section downstream of the Mostar Interchange (mark 1 in Fig. 3) which is also congested $(q / C=125 \%)$. An increase in speed in the tunnel to $80 \mathrm{~km} / \mathrm{h}$ has slightly relieved the Old Gazela Bridge compared to Scenario S2. Most of the urban highway sections are in a congested state as a result of urban highway attractiveness.

\section{Scenario 2:}

The most loaded section on the network in Scenario $\mathrm{S} 2$ is the same section on the Old Gazela bridge $\left(Q_{c}=\right.$ 5.778PC and $q / C=111 \%)$ and the section downstream of the Mostar Interchange which is also congested ( $q$ / $C=128 \%$ ). A slight increase in the flow is resulting from the defined free flow speed in the tunnel of $60 \mathrm{~km} / \mathrm{h}$ which further diminishes the competitiveness of an alternative route. Irrespectively of such a considerable change in free flow speed in the tunnel, a change in the flow is rather small which indicates small sensitivity to change speed on the alternative route.

\section{Scenario 3:}

The most loaded sections are the same as with the previous Scenarios and include the Old Gazela bridge $\left(Q_{c}=5.146 \mathrm{PC}\right.$ and $\left.q / C=100 \%\right)$ and the section downstream of the Mostar Interchange $(q / C=112 \%)$. As a consequence of decreased free flow speed, the number of vehicles in specific sections is smaller and the travellers more easily choose their alternative routes. This Scenario is operating at the limit of urban highway capacity. Although alternative routes provide satisfactory values of capacity utilization, it should be taken into account that higher flow was recorded on other bridges outside the zone of interest as a consequence of speeds defined in this way (Bress Paradox) (Vukanovic 1997). The trap of Bress Paradox was avoided by a screen line analysis of the crossing over the Sava River.

\section{Scenario 4:}

The same most loaded sections with the highest values of capacity utilization, the Old Gazela bridge $(q / C=113 \%)$ and the section downstream of the Mostar Interchange $(q / C=131 \%)$, are a consequence of even greater difference between free flow speed in the tunnel $\left(V_{0}=50\right)$ and free flow speed on the urban highway $\left(V_{0}=80\right)$.

\section{Scenario 5:}

The Old Gazela bridge section has boundary capacity utilization $\left(Q_{c}=5.023 \mathrm{PC}\right.$ and $\left.q / C=97 \%\right)$ while the section downstream of the Mostar Interchange is slightly congested $(q / C=103 \%)$. By reducing free flow speed on the urban highway, the alternative over the New Sava bridge gains added significance and load distribution between alternative routes is the most favourable one.

A graphic presentation of traffic load and derived indicators is made for each Scenario like in Figs 4 and 5. Such presentation is very clear for those decision makers who are not experts in the field of traffic.

\section{Analysis Of Modelling Results}

\section{Traffic load analysis}

In Scenarios 1, 2 and 4 with free flow speed on the urban highway of $V_{0}=80 \mathrm{~km} / \mathrm{h}$, the attractiveness of the urban highway is great. Hence, it dominantly influ- 


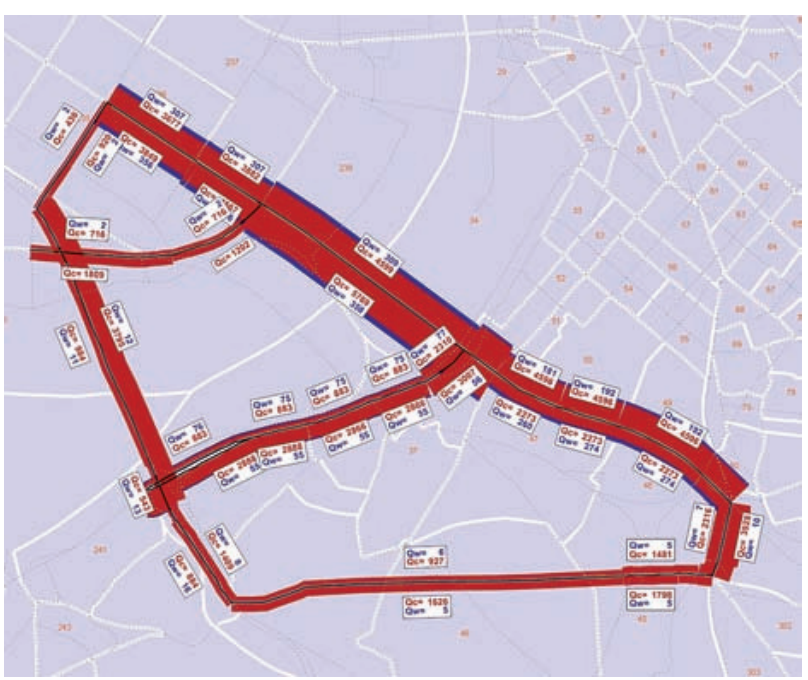

Fig. 4. Flows on network sections in Scenario 5

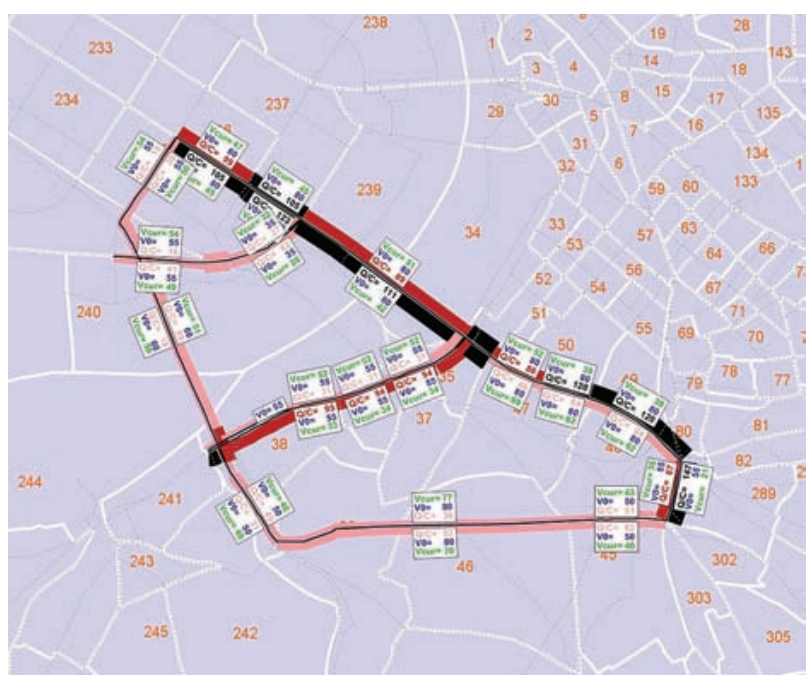

Fig. 5. Traffic network load indicators in Scenario 5

ences load distribution and attracts a great number of vehicles. The alternative route over the New Sava bridge introduced in this Scenario represents no valid alternative to the urban highway where flow exceeds its capacity, thus entering into the congestion state because of which exponential speed decreases from free flow speed to $35 \mathrm{~km} / \mathrm{h}$ which is a considerable drop in speed and the greatest drop in the Scenario with the lowest free flow speed on the alternative route $(50 \mathrm{~km} / \mathrm{h})$.

As regards freight vehicles, route selection cannot be influenced because of an effective decision regulating the routes on which the movement of freight vehicles is permitted. In this way, no great changes in freight traffic load occur. Therefore, in the Scenarios, these loads can be treated as constant loads.

As a critical point on the separated network there appears the section connecting alternative routes (section C3 in Fig. 3). It is the section that leads traffic coming from the peripheral areas of the City into the city centre. This section considerably influences speed on the alternative route over the new bridge and is detected as the network bottleneck.
When changing speeds in the tunnel, load on the transversal connection (section $\mathrm{C} 1$ in Fig. 3) does not change considerably. During a peak hour, this connection is at the limit of its capacity, and hence is unable to attract traffic.

The Scenarios predicting lower free flow speed on the urban highway ( 3 and 5) are favouring the use of the New Sava bridge. In this way, a balanced flow diagram on the entire observed network is obtained. Scenario 3 with equal speeds (60 on the urban highway and in the tunnel) only influences a decrease in load on both routes, whereas relations (proportionally) remained unchanged as in the Scenario with a speed of $80 \mathrm{~km} / \mathrm{h}$.

In Scenario 5 with speed on the urban highway $60 \mathrm{~km} / \mathrm{h}$ and $80 \mathrm{~km} / \mathrm{h}$ in the tunnel, volume to capacity ratio on the urban highway is close to 1 . On the other hand, volume to capacity ratio on the New Sava Bridge and in the tunnel increases.

The basic idea in Scenarios 3 and 5 is a reduction in free flow speed that depends on the profile. In order to achieve a free flow speed of $60 \mathrm{~km} / \mathrm{h}$, it is necessary to introduce speed restriction on the critical part of the urban highway. As this measure itself is not sufficient, a better treatment for on-ramps on the urban highway is proposed. For example, during a peak hour, the ramp could have a highway lane reserved for merging which should surely reduce free flow speed because urban highway profile should be reduced from the previous three lanes to two lanes. An interim solution is possible in which the use of the third lane would be allowed only for merging vehicles from the previous ramp as well.

Based on load analysis, Scenario 5 with a speed of $60 \mathrm{~km} / \mathrm{h}$ on the urban highway and $80 \mathrm{~km} / \mathrm{h}$ in the tunnel, was selected for further analysis. A comparison with Scenario 1 was made to quantify advantages and disadvantages. Such choice was made because the urban highway is the most important route in the City, particularly the Old Gazela Bridge defined as Corridor X bottleneck on the maps of world logistics. The intention was to show the difference in load as a result of changes in free flow speed on the urban highway.

Based on load analysis, data on noise level and air pollution parameters $\left(\mathrm{NO}_{\mathrm{X}}, \mathrm{CO}, \mathrm{SO}_{2}\right.$ and $\left.\mathrm{HC}\right)$ can be also obtained. Data on the environmental effects of these Scenarios can be compared with reference to which the generated Scenarios can be relatively ranked.

Fig. 6 provides a group presentation of environmental indicators which may be generated from the models offered by software. Relations contained in the models are mainly obtained employing empirical methods (PTV).

To be graphically presented, each environmental indicator may be independently treated, as shown in Fig. 7.

The economic effects of the proposed solutions on the selected Scenarios S1 and S5 were considered through data on vehicle-kilometres and vehicle-hours (Transportation System Performance 2007).

In Scenario 1, there were 71182 vehicle-km and in Scenario 5 it made 68746 vehicle-km. Vehicle-km were reduced by 2436 vehicle-km during a peak hour which 


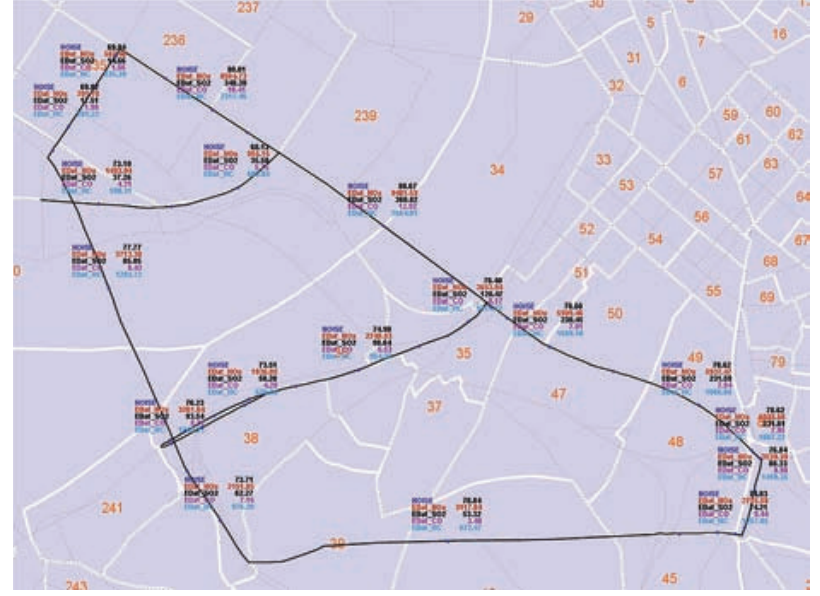

Fig. 6. Graphical presentation of environmental parameters in Scenario 5

Variant 1

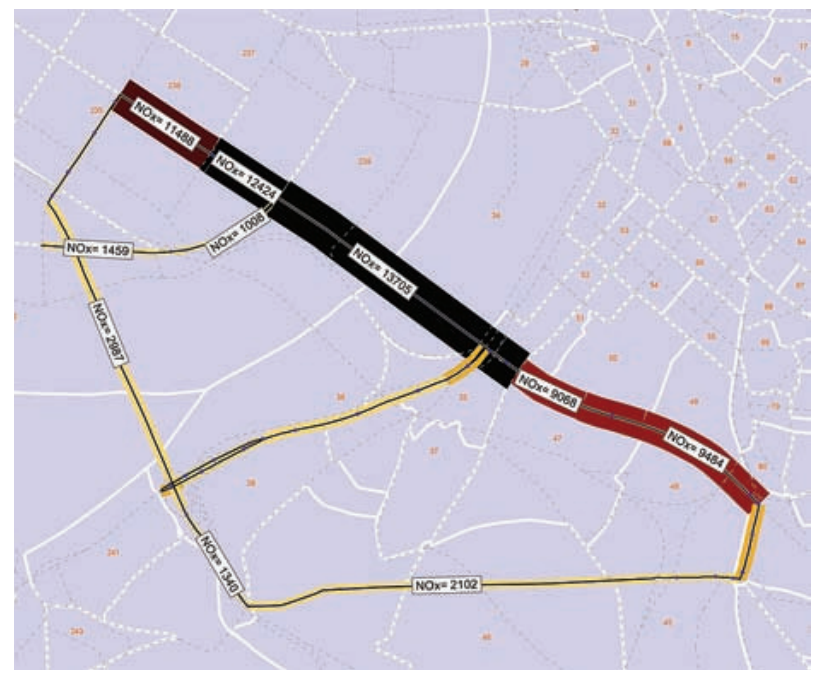

Variant 5

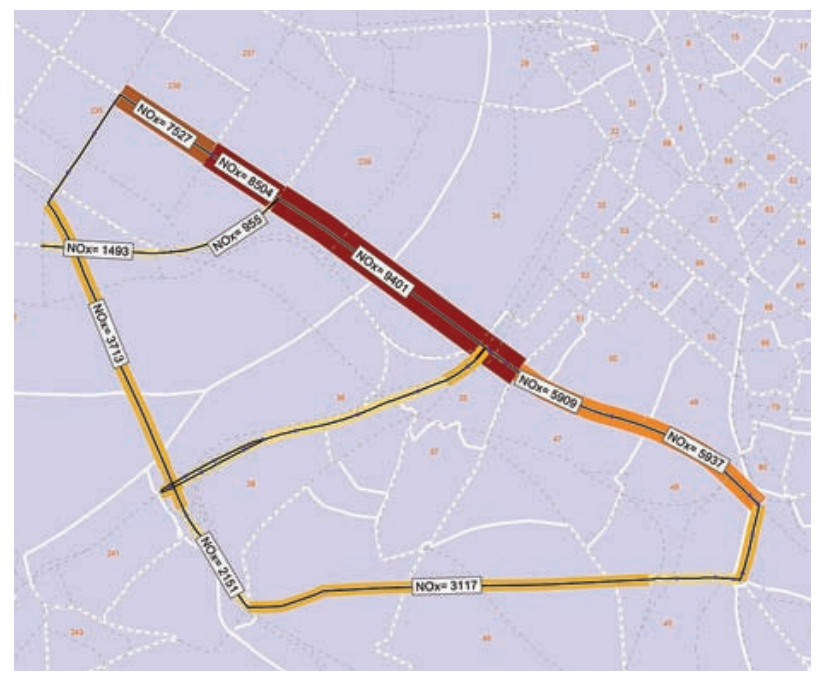

Fig 7. Comparative graphical presentation of $\mathrm{NO}_{\mathrm{x}}$ selected Scenarios

represents a decrease of $3.4 \%$ which is a consequence of shortening routes where vehicles move across the network accordingly to a change in speeds.
On the other hand, total travel time expressed in vehicle-hours in Scenario 1 is 1.630 and in Scenario 5 it makes 1.654 . Travel time increases by approximately 24 vehicle-hours which represents an increase of about $1.5 \%$. Travel time also increases as a consequence of a change in travel speed. Better load distribution is achieved on the network together with more balanced utilisation of capacity but lower travel speeds.

\section{Conclusions}

1. Traffic planning cannot be treated as an objective but is rather shaping the transport system so as to become compliant with the principles of sustainability in order to derive optimal functions from the system with defined physical characteristics and having minimum utilization of resources in the operation phase. Energy efficiency at the time of energy shortage plays an important role for traffic and the list of traffic infrastructure priority (Saunders et al. 2008). New technical solutions and transport systems enable many options in the development of the system having to accommodate growing transport demands.

2. Transportation modelling is the most efficient way to analyze the effects of traffic solutions. The benefits of the approach are the possibility of working with a large number of developed scenarios and fast scenario modification producing and testing the new ones.

3. Once established, a transport model brings not only benefits to the future projects, considering more economical project production and higher quality but also requires constant maintenance, calibration and validation expressing changes in the transport system.

4. Speed reduction strategy was easily simulated using the transportation modelling procedure the results of which were used to present clear and understandable output displaying graphics and tables.

5. Other sustainable transport and mobility management strategies considering sustainable transportation could also be simulated.

6. From the point of view of traffic, the best solution may not be optimal from an ecological point of view (Jovic and Djoric, 2009).

7. A lot has been achieved in Belgrade in the last few years. Several capital projects have been initiated and the most interesting among them are the City Bypass (about $50 \%$ of the project completed), the New Sava bridge (the final phase, will be completed in 36 months) and the Inner Semi-Ring Road (preparatory phase). Extensive transport demand analyses considering various time horizons were made on all Projects using the Transport Model of Belgrade.

8. The previous analyses and assessments of the effects of planning measures provide considerable savings related to the 'blind' implementation of measures. By modelling transport demands and transport system supply, it is possible to quantify the impact of the envisaged actions and loading of routes as well as a great number of derived traffic effects (Djoric 2007, 2008).

9. The effects of time or a spatial dislocation of the problem are also avoided solving some specific problems 
this way. A problem of identical or higher intensity may appear in other period of time or on the other part of the traffic network which most easily can be perceived on the graphical presentations of the network.

10. The Transport Model of Belgrade was made applying software package VISION in the part of the program for traffic planning and macro-simulation (VISUM). The model is iteratively improved inserting data on a higher level of detail. The program is GIS-based, thus enabling referencing and filtering a great number of data. However, the basic advantage lies in the possibility of overlapping various transport systems, traffic modelling of the system and the events occurring in the systems.

11. By aggregating all data within the model, it is possible to create a complete database representing a basis for all analyses to be performed in the future which is vitally important because this way, the possibility of input data manipulation is eliminated.

12. Thus, the created model enables the presentation of traffic system load in a sufficiently precise manner. A great number of system Scenarios are created simply by changing relevant transport system parameters. It is easy to perform the quantification of the obtained output indicators (both traffic and environmental) that are sufficient indicators of the quality of the applied planning measures and changes on the network. The output from macro-simulation represents input data for micro simulation which processes the obtained results at a higher level of detail.

13. A graphic and tabular presentation of data provides a possibility of presenting all information from the database in the form enabling the demonstration of the obtained results in the most simplest and precise way. It is very important to provide a uniform presentation of the results for decision makers who are not very often experts in the subject matter because development policy is going to be created on the basis of such results. Taking into account the absolute values of this data, it is used to present the measure of the realized improvements and worsening, whereas on the other hand, it serves as input into the process of evaluating traffic solutions. The possibility of presenting and quantifying environmental effects is emphasised as an important segment.

\section{References}

André, M.; Hammarström, U. 2000. Driving speeds in Europe for pollutant emissions estimation, Transportation Research Part D: Transport and Environment 5(5): 321-335. doi:10.1016/S1361-9209(00)00002-X

Bazaras, J.; Jablonskyte, J.; Jotautienè, E. 2008. Interdependence of noise and traffic flow, Transport 23(1): 67-72. doi:10.3846/1648-4142.2008.23.67-72

Burinskienè, M. 2009. New methodology for sustainable development towards sustainable transportation system, Technological and Economic Development of Economy 15(1): 5-9. doi:10.3846/1392-8619.2009.15.5-9
Burinskienè, M.; Rudzkienè, V. 2009. Future insights, scenarios and expert method application in sustainable territorial planning, Technological and Economic Development of Economy 15(1): 10-25. doi:10.3846/1392-8619.2009.15.10-25

Daunoras, J.; Bagdonas, V.; Gargasas, V. 2008. City transport monitoring and routes optimal management system, Transport 23(2): 144-149. doi:10.3846/1648-4142.2008.23.144-14

Djoric, V. 2007. Modeliranje ekoloških parametara pomoću programskog paketa VISUM na osnovu Transportnog modela Beograda [Ecological parameters modeling using VISUM program pack on basis of transportation model of Belgrade], Tehnika - Saobraćaj 16(5): 11-18.

Djoric, V. 2008. Modeliranje transportnih zahteva sa aspekta održivog transporta i energetske efikasnosti [Transportation demand modeling: sustainable transport and energy efficiency aspect], Tehnika - Saobraćaj 17(6): 17-24.

Filipović, S.; Tica, S.; Živanović, P.; Milovanović, B. 2009. Comparative analysis of the basic features of the expected and perceived quality of mass passenger public transport service in Belgrade, Transport 24(4): 265-273. doi:10.3846/1648-4142.2009.24.265-273

Jovic, J. 2003. Modern tools in transportation planning: transport model of Belgrade, Transporti Europei [European Transport] 24: 31-38.

Jovic, J. et al. 2006. Analiza saobraćajnih opterećenja u zoni unutrašnjeg magistralnog poluprstena od ulice Omladinskih brigada do ulice Paštrovićeve primenom transportnog modela [Traffic assignment analysis on Belgrade semi-ring using transportation model of Belgrade]. University of Belgrade, Serbia.

Jovic, J. et al. 2007. Transportni model Beograda [Transport model of Belgrade]. University of Belgrade, Serbia.

Jovic, J. et al. 2008. Modeliranje transportnih potreba u funkciji zahteva mobilnosti i energetske efikasnosti gradova [Transportation Demand Modeling for Transportation Demand Management and Energie Eficiency of Cities]. Ministry of Science and Technological Development. Project in progress. Serbia.

Jovic, J.; Djoric, V. 2009. Application of transport demand modeling in pollution estimation of a street network, Thermal Science 13(3): 229-243. doi:10.2298/TSCI0903229J

Kinderytė-Poškienė, J.; Sokolovskij, E. 2008. Traffic control elements influence on accidents, mobility and the environment, Transport 23(1): 55-58. doi:10.3846/1648-4142.2008.23.55-58

Kovács, V. B.; Török, Á. 2010. Investigation on transport related biogas utilization, Transport 25(1): 77-80. doi:10.3846/ transport.2010.10

Kuprys, A.; Kugelevičius, J. 2009. Possibilities of using liquefied oil gas in transport, Transport 24(1): 48-53. doi:10.3846/1648-4142.2009.24.48-53

Litman, T. 2010a. Smart Transportation Emission Reductions: Identifying Truly Optimal Energy Conservation and Emission Reduction Strategies. Victoria Transport Policy Institute. 21 p. Available from Internet: $<$ www.vtpi.org/ster.pdf $>$.

Litman, T. 2010b. Win-Win Emission Reduction Strategies: Smart Transportation Strategies Can Achieve Emission Reduction Targets and Provide other Important Economic, Social and Environmental Benefits. Victoria Transport Policy Institute. 15 p. Available from Internet: $<$ www.vtpi.org/wwclimate.pdf $>$.

Lumbreras, J.; Valdés, M.; Borge, R.; Rodríguez, M. E. 2008. Assessment of vehicle emissions projections in Madrid 
(Spain) from 2004 to 2012 considering several control strategies, Transportation Research Part A: Policy and Practice 42(4): 646-658. doi:10.1016/j.tra.2008.01.026

Mačiulis, A.; Vasilis Vasiliauskas, A.; Jakubauskas, G. 2009. The impact of transport on the competitiveness of national economy, Transport 24(2): 93-99.

doi:10.3846/1648-4142.2009.24.93-99

New Directions in Speed Management: A Review of Policy. 2009. Department for Transport, UK. Available from Internet: $<$ www.dft.gov.uk/pgr/roadsafety/speedmanagement/newdirectionsinspeedmanageme4802>.

Online TDM Encyclopedia. 2009. Victoria Transport Policy Institute. Available from Internet: <www.vtpi.org/tdm $>$.

Paslawski, J. 2009. Flexibility in highway noise management, Transport 24(1): 66-75.

doi:10.3846/1648-4142.2009.24.66-75

Saunders, M. J.; Kuhnimhof, T.; Chlond, B.; Rodrigues da Silva, A. N. 2008. Incorporating transport energy into urban planning, Transportation Research Part A: Policy and Practice 42(6): 874-882. doi:10.1016/j.tra.2008.01.031

Szűcs, G. 2009. Developing co-operative transport system and route planning, Transport 24(1): 21-25. doi:10.3846/1648-4142.2009.24.21-25

Smartplan Beograda [Smartplan of Belgrade 2021]. 2001. Urban Planning Institute of Belgrade, Belgrade, Serbia.

Tanczos, K.; Torok, A. 2008. Introducing decisive development orientations into transport modeling, Transport 23(4): 330334. doi:10.3846/1648-4142.2008.23.330-334

Toward a Sustainable Future. 1997. Transportation Research Board Special Report 251. Washington DC. Available from Internet: $<$ http://onlinepubs.trb.org/onlinepubs/sr/sr251.pdf $>$.

Török, Á. 2009. Theoretical estimation of the environmental impact of biofuel mixtures, Transport 24(1): 26-29. doi:10.3846/1648-4142.2009.24.26-29

Transportation System Performance. 2007. US Department of Transportation, Federal Highway Administration. Available from Internet: <www.fhwa.dot.gov/Planning/toolbox/ transperf_overview.htm $>$.

VISUM 10.0 User Manual. 2007. PTV Planung Transport Verkehr AG.

Urban Environmental Management Guiding Principles for Sustainable Transportation. 2009. The Global Development Research Center. Available from Internet: <www.gdrc.org/ uem/sustran/sustran.html >.

Ušpalytė-Vitkūnienė, R.; Burinskienè, M.; Grigonis, V. 2006. Calibration of Vilnius public transport model, Transport 21(3): 201-206.

Vuchic, V. R. 1999. Transportation for Livable Cities. Center for Urban Policy Research. 352 p.

Vukanovic, S. 1997. Saobraćajne mreže I [Transportation networks I]. University of Belgrade, Serbia

Vukanovic, S., et al. 2006. Database for Economic Evaluations of Transport Infrastructure Projects in Belgrade Area. University of Belgrade, Serbia. 